\title{
Wyznaczanie naprężeń obliczeniowych w spoinach pachwinowych w złożonych stanach obciążeń - zgodnie z Eurokodem 3
}

\section{Method for analytical computation of stresses in fillet joints for complex load states - according to Eurocode 3}

\section{Streszczenie}

Praca zawiera opis metodyki obliczeń nośności statycznej spoin pachwinowych dwoma dopuszczonymi przez Eurokod 3 sposobami: kładowym (uproszczonym) i kierunkowego rozkładu naprężeń, opartym na wszechstronnych badaniach wytrzymałości spoin i hipotezie $\mathrm{HMH}$.

Przedstawiono przykład wyznaczania naprężeń obliczeniowych w spoinie pachwinowej obciążonej trzema wzajemnie prostopadłymi siłami, wywołującymi siedem różnych rodzajów naprężeń. Dokonano ich rozkładu, a następnie superpozycji w kluczowych punktach spoiny. Wyjaśniono dlaczego metoda kładowa (uproszczona) prowadzi do obliczeniowego przewymiarowywania spoin pachwinowych.

Słowa kluczowe: Eurokod 3, nośność złączy, spoiny pachwinowe, złożone obciążenia

\section{Abstract}

The paper describes methodology for calculation of fillet joint load capacity using two approaches allowed by Eurocode 3: projection method (simplified) and method of directional stress distribution that is based on comprehensive weld strength tests and $\mathrm{HMH}$ hypothesis.

The work presents the example of stress calculation for fillet joints loaded with three forces acting along mutually perpendicular directions that produce stresses of seven different kinds. The stress decomposition and subsequently stress superposition in key weld points was performed. It was explained why projection method (simplified) leads to computational overestimation of fillet joints.

Keywords: Eurocode 3, joint load capacity, fillet joints, complex load state

\section{Wstęp}

Obliczanie pochodzących od obciążeń zewnętrznych naprężeń w spoinach pachwinowych podlegało w ciągu ostatnich kilkudziesięciu lat licznym korektom $[1 \div 5]$. Początkowo uznawano, że wobec faktu niszczenia przez ścinanie spoin pachwinowych w ich powierzchni dwusiecznej, obliczając wszelkie naprężenia można wykonać jej kład o kąt $45^{\circ}$ (dla spoin równoramiennych) na płaszczyznę rysunku (rys. 1).

\begin{abstract}
Uzyskiwane w ten sposób pole lub wskaźnik uznawano za czynniki nośne przy wyznaczaniu naprężeń, które zawsze były ścinające [1]. Metoda ta była nie tylko paradoksalna, gdyż przewidywała występowanie naprężeń stycznych w trzech, wzajemnie prostopadłych kierunkach, lecz również wskutek swej niedokładności prowadziła do znacznego, kilkunasto-kilkudziesięcioprocentowego przewymiarowywania spoin [6]. Jej stosowanie dopuszcza Eurokod 3, jako metodę uproszczoną, gdyż nie wymaga rozkładu sił działających na spoinę.
\end{abstract}

Dr inż. Krzysztof Kudła, dr inż. Kwiryn Wojsyk - Politechnika Częstochowska. 


\section{Określanie nośności spoin pachwinowych w złożonych stanach naprężenia}

Liczne badania nośności spoin pachwinowych w złożonych stanach naprężeń doprowadziły - początkowo w przypadkach szczególnych [2] - a następnie ogólnych, do wyznaczenia pełnej elipsoidy wytrzymałości spoin pachwinowych dla różnych stali [7], a następnie ustalenia wzorów opartych na hipotezie Hubera-Misesa-Hencky'ego [5, 8] (rys. 2.) W przeciwieństwie do Kładowej Metody Uproszczonej, Metoda Kierunkowa rozkładu naprężeń na płaszczyznę dwusieczną spoiny lepiej przystaje do rzeczywistego mechanizmu eksploatacyjnego pękania spoin pachwinowych.

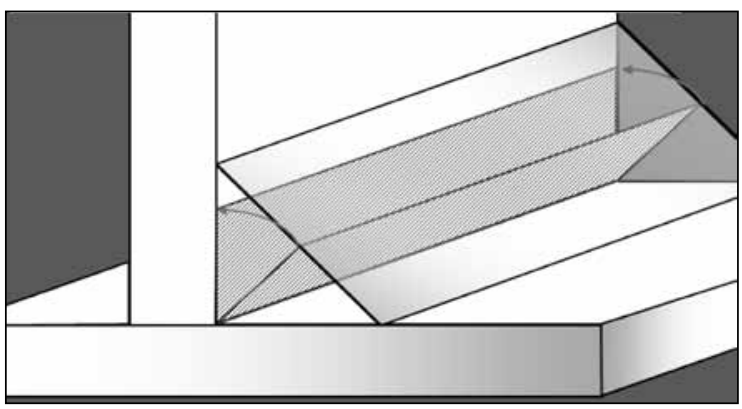

Rys. 1. Operacja kładu obliczeniowej płaszczyzny graniowej (dwusiecznej) spoiny pachwinowej na płaszczyznę rysunku

Fig. 1. Projection of the root (bisecting) plane of fillet joint on the surface of a drawing

Metoda ta jest metodą ogólną, stosunkowo wiernie obrazującą nośność spoin pachwinowych pod wpływem obciążeń zewnętrznych. Przyjmuje się, że nie ma spiętrzenia naprężeń na końcach spoiny, a rozkład naprężeń jest równomierny w całym przekroju [8]. Dla dłuższych niż 150 a spoin pachwinowych w złączach zakładkowych zaleca się zmniejszenie ich nośności współczynnikiem redukcyjnym:

$$
\beta_{l w 1}=1,2-\frac{0,2 l_{w}}{150 a} \leq 1,0
$$

a)

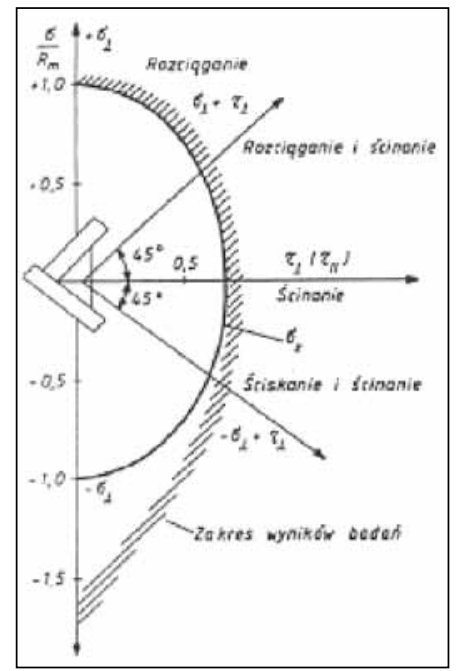

a w przypadku spoin dłuższych niż łączących żebra w elementach blachownicowych przyjmuje się współczynnik redukcyjny:

$$
\beta_{l w 2}=1,1-\frac{l_{w}}{17} \leq 1,0 \quad \beta_{l w 2} \geq 0,6
$$

gdzie:

$\mathrm{I}_{\mathrm{w}}$ - długość spoiny [m] [5],

$\beta_{\mathrm{lw} 1}, \beta_{\mathrm{lw} 2}-$ współczynniki korekcyjne zmniejszające nośność spoiny pachwinowej,

a - grubość spoiny pachwinowej (rys. 2).

Nośność obliczeniową oblicza się ze wzorów:

$$
\begin{aligned}
& \sigma_{z}=\sqrt{\sigma_{\perp}^{2}+3\left(\tau_{\perp}^{2}+\tau_{1}^{2}\right)} \leq \frac{f_{u}}{\beta_{w} \cdot \gamma_{M 2}} \\
& \sigma_{\perp} \leq 0,9 \frac{f_{u}}{\gamma_{M z}}
\end{aligned}
$$

gdzie:

$\sigma_{\perp}, \tau_{\perp}, \tau$-składowe stanu naprężeń w przekroju spoiny, odpowiednio normalne i styczne do płaszczyzny przekroju (rys. 2b),

$f u$ - nominalna wytrzymałość na rozciąganie słabszego $z$ łączonych materiałów - w zakresie $360 \div 560 \mathrm{MPa}$ dla $\mathrm{t} \leq 40 \mathrm{~mm}$ i $340 \div 550 \mathrm{MPa}$ dla $40 \mathrm{~mm}<\mathrm{t} \leq 80 \mathrm{~mm}$,

$\beta_{w}$ - współczynnik korelacji uwzględniający wyższe właściwości mechaniczne materiału spoiny w stosunku do materiału.

$\gamma_{\mathrm{M} 2}=1,25$ - współczynnik bezpieczeństwa przy sprawdzaniu nośności na rozerwanie.

Tablica I. Wyniki oznaczania ilości wodoru dyfundującego w stopiwie Table I. Results of determination of diffusible hydrogen content in deposited metal

\begin{tabular}{|c|c|}
\hline Gatunek stali & $\beta_{\text {lw }}$ \\
\hline S235 & 0,8 \\
\hline S275 & 0,85 \\
\hline S355 & 0,9 \\
\hline S420 & 1,0 \\
\hline S460 & 1,0 \\
\hline
\end{tabular}

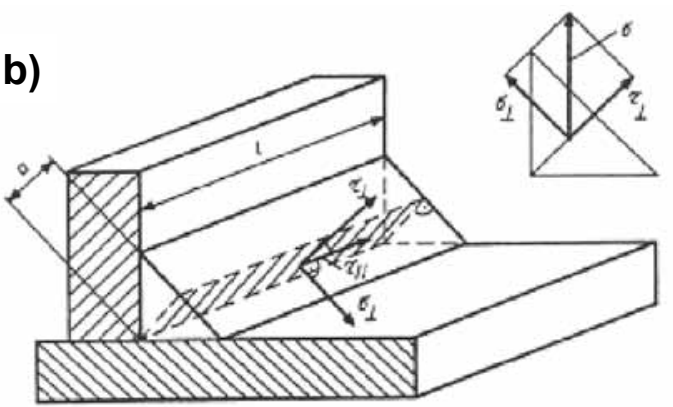

Rys. 2. a) Przebieg zmian naprężenia w zależności od kierunku działania obciążenia, określony wg wzoru ISO/IIW i doświadczalnie; b)rozkład naprężeń zewnętrznych na składowe - na płaszczyznę dwusieczną spoiny pachwinowej

Fig. 2. a) Dependency of stress on the direction of load, determined according to ISO/IIW norm and experimentally; b) the decomposition of external stresses into the bisecting plane of a fillet joint 
W spoinach o przekroju równoramiennego trójkąta prostokątnego (pachwin symetrycznych):

$$
\begin{aligned}
& \sigma_{\perp}=\tau_{\perp}=\frac{\sqrt{2}}{2} \sigma \\
& \sigma_{\perp}=\tau_{\perp}=\frac{\sqrt{2}}{2} \tau
\end{aligned}
$$

Warunek (4) nie wymaga wtedy sprawdzania, gdyż jest zawsze spełniony. Pomimo swej prostoty, obliczanie naprężeń w spoinach pachwinowych metodą kierunkową sprawiać może nieco kłopotów osobom, które rzadko mają do czynienia z projektowaniem złączy spawanych oraz inżynierom korzystającym wcześniej ze starszej literatury lub dopuszczonej Eurokodem 3 metody kładowej. We wcześniejszej pracy [9] zaprezentowano przykład obliczeniowy według dotychczas obowiązującej PN-90/B-03200, jednak nieobejmujący trudniejszych do wyznaczenia naprężeń w punktach pozaosiowych. Lukę tę wobec ciągłego wzrostu wymagań technologicznych i normatywnych $[11 \div 14]$ starano się wypełnić niniejszym opracowaniem.

Przykład. Okrągły pręt stalowy przyspawano spoiną pachwinową do stalowej ściany. Obliczyć naprężenia w punktach $1 \div \vee$ złącza pokazanego na rysunku 3 , jeżeli działa na nie zewnętrzna siła $\mathrm{P}$.

\section{Obliczenie statycznych wielkości spoiny:}

$$
F_{s p}=\frac{\pi}{4}\left[(d+2 a)^{2}-d^{2}\right]
$$

- osiowy moment bezwładności względem osi obojętnej:

$$
I_{x_{o}}=I_{y_{o}}=\frac{\pi}{64}\left[(d+2 a)^{4}-d^{4}\right] \text {, }
$$

- biegunowy moment bezwładności względem środka spoiny:

$$
\mathrm{I}_{\mathrm{o}}=\mathrm{I}_{\mathrm{x}_{\mathrm{o}}}+\mathrm{I}_{\mathrm{y}_{\mathrm{o}}}=\frac{\pi}{32}\left[(\mathrm{~d}+2 \mathrm{a})^{4}-\mathrm{d}^{4}\right]
$$

- wskaźnik wytrzymałości na zginanie względem osi obojętnej:

$$
\mathrm{W}_{\mathrm{x}_{\mathrm{o}}}=\mathrm{W}_{\mathrm{y}_{\mathrm{o}}}=\frac{\mathrm{I}_{\mathrm{x}_{\mathrm{o}}}}{\frac{\mathrm{d}+2 \mathrm{a}}{2}}=\frac{\pi}{32} \frac{\left[(\mathrm{d}+2 \mathrm{a})^{4}-\mathrm{d}^{4}\right]}{\mathrm{d}+2 \mathrm{a}}
$$

- wskaźnik wytrzymałości na skręcanie względem środka obrotu:

$$
\mathrm{W}_{\mathrm{o}}=\frac{\mathrm{I}_{\mathrm{o}}}{\frac{\mathrm{d}+2 \mathrm{a}}{2}}=\frac{\pi}{16} \frac{\left[(\mathrm{d}+2 \mathrm{a})^{4}-\mathrm{d}^{4}\right]}{\mathrm{d}+2 \mathrm{a}}
$$

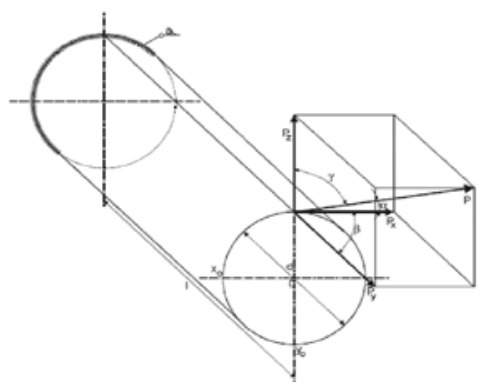

Rys. 3. Usytuowanie obciążenia $P$ względem spoiny pachwinowej Fig. 3. The position of load $P$ relative to a fillet joint

Obliczenie składowych obciążenia P, położonych prostopadle lub równolegle do płaszczyzny rysunku:

$$
\begin{aligned}
& P_{x}=p \cos \alpha \\
& P_{y}=\cos \beta \\
& P_{z}=p \cos \gamma
\end{aligned}
$$

\section{Ustalenie rodzajów i wielkości naprężeń pochodzących od sił składowych:}

Siła $P_{x}$ wywołuje:

- ścinanie

$$
{ }^{t} \tau^{P_{x}}=\frac{P_{x}}{F_{s p}}
$$

- skręcanie

$$
{ }^{\mathrm{s}} \tau^{\mathrm{P}_{\mathrm{x}}}=\frac{\mathrm{M}_{\mathrm{s}}^{\mathrm{P}_{\mathrm{x}}}}{\mathrm{W}_{\mathrm{o}}}
$$

gdzie:

$$
\mathrm{M}_{\mathrm{s}}^{\mathrm{P}_{\mathrm{x}}}=\mathrm{P}_{\mathrm{x}} \cdot \frac{\mathrm{d}}{2}
$$

- zginanie względem osi $y_{\circ} \quad{ }^{g} \sigma^{P_{x}}=\frac{M_{g}^{P_{x}}}{W_{y_{o}}}$ gdzie: $\quad \mathrm{M}_{\mathrm{g}}^{\mathrm{P}_{\mathrm{x}}}=\mathrm{P}_{\mathrm{x}} \cdot 1$

Siła $P_{y}$ wywołuje:

- rozciąganie

$$
{ }^{r} \sigma^{P_{y}}=\frac{P_{y}}{F_{s p}}
$$

- zginanie względem osi $x_{o} \quad{ }^{g} \sigma^{P_{y}}=\frac{M_{g}^{P_{y}}}{W_{x_{o}}}$

gdzie:

$$
\mathrm{M}_{\mathrm{g}}^{\mathrm{P}_{\mathrm{y}}}=\mathrm{P}_{\mathrm{y}} \cdot \frac{\mathrm{d}}{2}
$$

Siła $\mathrm{P}_{\mathrm{z}}$ wywołuje:

- ścinanie

$$
{ }^{t} \tau^{P_{z}}=\frac{P_{z}}{F_{s p}}
$$

- zginanie względem osi $\mathrm{x}_{\mathrm{o}} \quad{ }^{\mathrm{g}} \sigma^{\mathrm{P}_{\mathrm{z}}}=\frac{\mathrm{M}_{\mathrm{g}}^{\mathrm{P}_{\mathrm{z}}}}{\mathrm{W}_{\mathrm{x}_{\mathrm{o}}}}$

gdzie:

$$
\mathrm{M}_{\mathrm{g}}^{\mathrm{P}_{\mathrm{z}}}=\mathrm{P}_{\mathrm{z}} \cdot 1
$$




\section{Określenie skutków działania składowych siły $\mathrm{P}$ w punktach I-IV obwodu spoiny:}

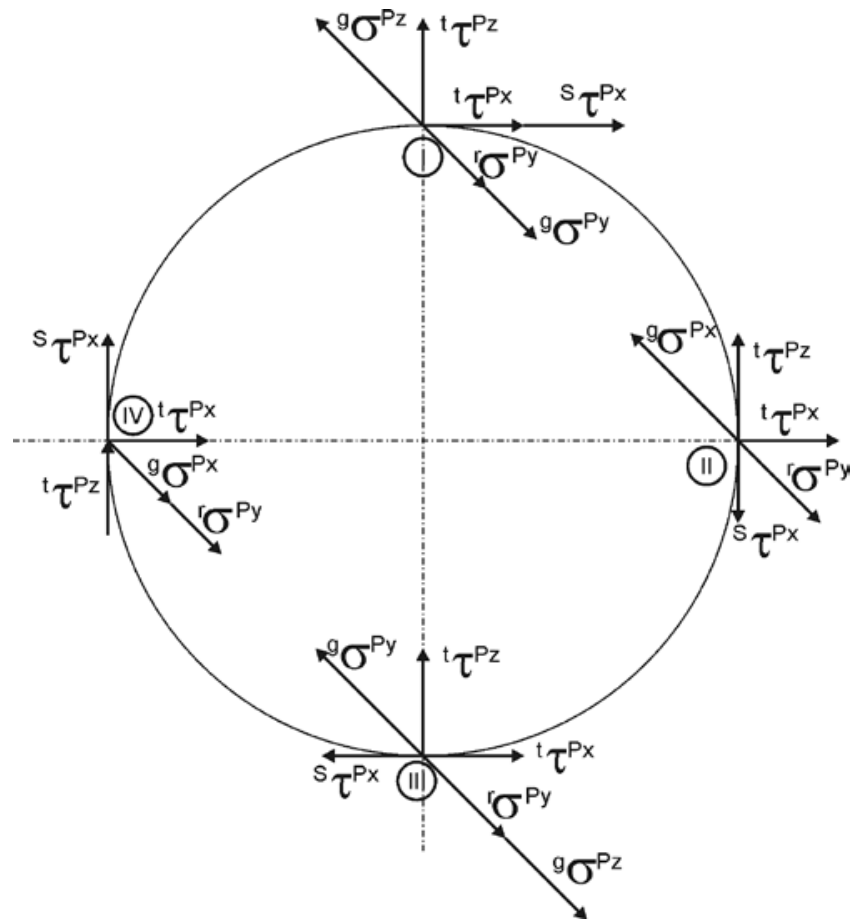

Rys. 4. Rozkład naprężeń normalnych i stycznych do płaszczyzny rysunku w czterech punktach obwodu spoiny pachwinowej

Fig. 4. The distribution of normal and shear stresses in the drawing plane at four points along the contour of the fillet joint

\section{Metoda kładowa}

W przypadku obliczania spoin pachwinowych metodą kładową należy naprężenia normalne $\sigma$ z rysunku 4 potraktować jako styczne - ze względu na ich symetrię do $\tau_{\perp}$. Jak wspomniano wcześniej, wszelkie naprężenia w tej metodzie traktuje się jako styczne do obliczanego przekroju, chociaż takie nie są. Zatem sumaryczne naprężenia od siły $\mathrm{P}$ w punktach I $\div$ IV mają wartości:

Punkt 1, rysunek 4

$\tau_{z}(l)=\sqrt{\left(g_{\tau}^{P_{y}}+r_{\tau} P_{y}-g_{\tau} P_{z}\right)^{2}+\left({ }_{\tau} P_{z}\right)^{2}+\left({ }_{\tau} P_{x}+s_{\tau} P_{x}\right)^{2}} \leq \frac{f_{u}}{\sqrt{3} \beta_{w} \gamma_{M 2}}$

Punkt 2, rysunek 4

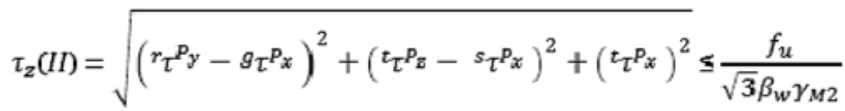

Punkt 3, rysunek 4

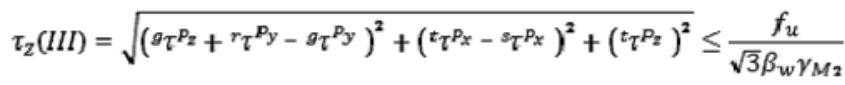

Punkt 4, rysunek 4

$\tau_{z}(I V)=\sqrt{\left({ }^{r^{P_{y}}}+{ }^{g} \tau^{P_{x}}\right)^{2}+\left({ }^{t} \tau^{P_{x}}\right)^{2}+\left({ }^{t} \tau^{P_{z}}+{ }^{s} \tau^{P_{x}}\right)^{2}} \leq \frac{f_{u}}{\sqrt{3} \beta_{w} \gamma_{M z}}$
Metoda kierunkowa

Punkt I, rysunek 5

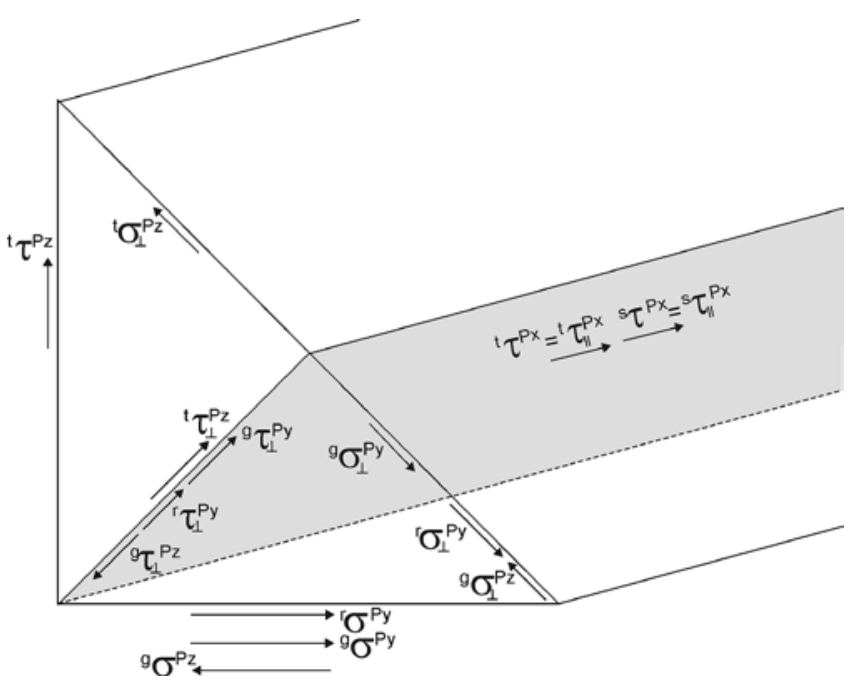

Rys. 5. Rozkład naprężeń w punkcie I spoiny pachwinowej

Fig. 5. The stress distribution at point I of the fillet joint

gdzie:

${ }^{\mathrm{t}} \tau^{\mathrm{P}_{\mathrm{x}}}={ }^{\mathrm{t}} \tau_{\mathrm{I}}^{\mathrm{P}_{\mathrm{x}}} \quad{ }^{\mathrm{s}} \tau^{\mathrm{P}_{\mathrm{x}}}={ }^{\mathrm{s}} \tau_{\mathrm{I}}^{\mathrm{P}_{\mathrm{x}}}$

${ }^{\mathrm{r}} \tau_{\perp}^{\mathrm{P}_{\mathrm{y}}}={ }^{\mathrm{r}} \sigma_{\perp}^{\mathrm{P}_{\mathrm{y}}}=\frac{\sqrt{2}}{2}{ }^{\mathrm{r}} \sigma^{\mathrm{P}_{\mathrm{y}}} \quad{ }^{\mathrm{g}} \tau_{\perp}^{\mathrm{P}_{\mathrm{y}}}={ }^{\mathrm{g}} \sigma_{\perp}^{\mathrm{P}_{\mathrm{y}}}=\frac{\sqrt{2}}{2}{ }^{\mathrm{g}} \sigma^{\mathrm{P}_{\mathrm{y}}}$

${ }^{\mathrm{g}} \tau_{\perp}^{\mathrm{P}_{\mathrm{z}}}={ }^{\mathrm{g}} \sigma_{\perp}^{\mathrm{P}_{\mathrm{z}}}=\frac{\sqrt{2}}{2}{ }^{\mathrm{g}} \sigma^{\mathrm{P}_{z}}{ }^{\mathrm{t}} \tau_{\perp}^{\mathrm{P}_{\mathrm{z}}}={ }^{\mathrm{t}} \sigma_{\perp}^{\mathrm{P}_{\mathrm{z}}}=\frac{\sqrt{2}}{2}{ }^{\mathrm{t}} \tau^{\mathrm{P}_{\mathrm{z}}}$

Zatem, zgodnie $\mathrm{z}$ zależnością $\mathrm{z}$ rysunku $2 \mathrm{~b}$, otrzymujemy:

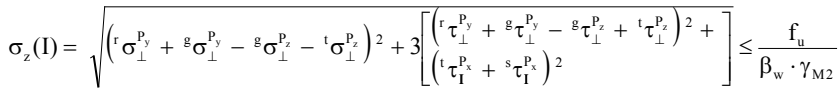

${ }^{\mathrm{r}} \sigma_{\perp}^{\mathrm{P}_{\mathrm{y}}}+{ }^{\mathrm{g}} \sigma_{\perp}^{\mathrm{P}_{\mathrm{y}}}-{ }^{\mathrm{g}} \sigma_{\perp}^{\mathrm{P}_{\mathrm{z}}}-{ }^{\mathrm{t}} \sigma_{\perp}^{\mathrm{P}_{\mathrm{z}}} \leq 0,9 \frac{\mathrm{f}_{\mathrm{u}}}{\gamma_{\mathrm{M} 2}}$

Punkt II, rysunek 6

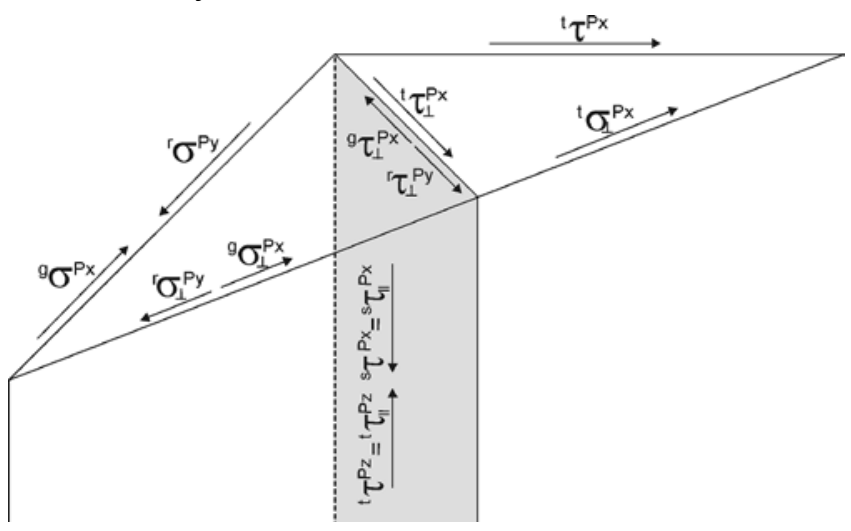

Rys. 6. Rozkład naprężeń w punkcie Il spoiny pachwinowej

Fig. 6. The stress distribution at point II of the fillet joint 
gdzie:

${ }^{\mathrm{t}} \tau_{\perp}^{\mathrm{P}_{\mathrm{x}}}={ }^{\mathrm{t}} \sigma_{\perp}^{\mathrm{P}_{\mathrm{x}}}=\frac{2}{\sqrt{2}}{ }^{\mathrm{t}} \tau^{\mathrm{P}_{\mathrm{x}}} \quad{ }^{\mathrm{s}} \tau_{\mathrm{I}}^{\mathrm{P}_{\mathrm{x}}}={ }^{\mathrm{s}} \tau^{\mathrm{P}_{\mathrm{x}}}$

${ }^{\mathrm{g}} \tau_{\perp}^{\mathrm{P}_{\mathrm{x}}}={ }^{\mathrm{g}} \sigma_{\perp}^{\mathrm{P}_{\mathrm{x}}}=\frac{\sqrt{2}}{2}{ }^{\mathrm{g}} \sigma^{\mathrm{P}_{\mathrm{x}}}{ }^{\mathrm{r}} \tau_{\perp}^{\mathrm{P}_{\mathrm{y}}}={ }^{\mathrm{r}} \sigma_{\perp}^{\mathrm{P}_{\mathrm{y}}}=\frac{\sqrt{2}}{2}{ }^{\mathrm{r}} \sigma^{\mathrm{P}_{\mathrm{y}}}$

${ }^{\mathrm{t}} \tau_{\mathrm{I}}^{\mathrm{P}_{\mathrm{z}}}={ }^{\mathrm{t}} \tau^{\mathrm{P}_{\mathrm{z}}}$

zatem:

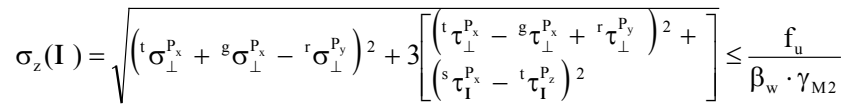

${ }^{\mathrm{t}} \sigma_{\perp}^{\mathrm{P}_{\mathrm{x}}}+{ }^{\mathrm{g}} \sigma_{\perp}^{\mathrm{P}_{\mathrm{x}}}-{ }^{\mathrm{r}} \sigma_{\perp}^{\mathrm{P}_{\mathrm{y}}} \leq 0,9 \frac{\mathrm{f}_{\mathrm{u}}}{\beta_{\mathrm{M} 2}}$

\section{Punkt III, rysunek 7}

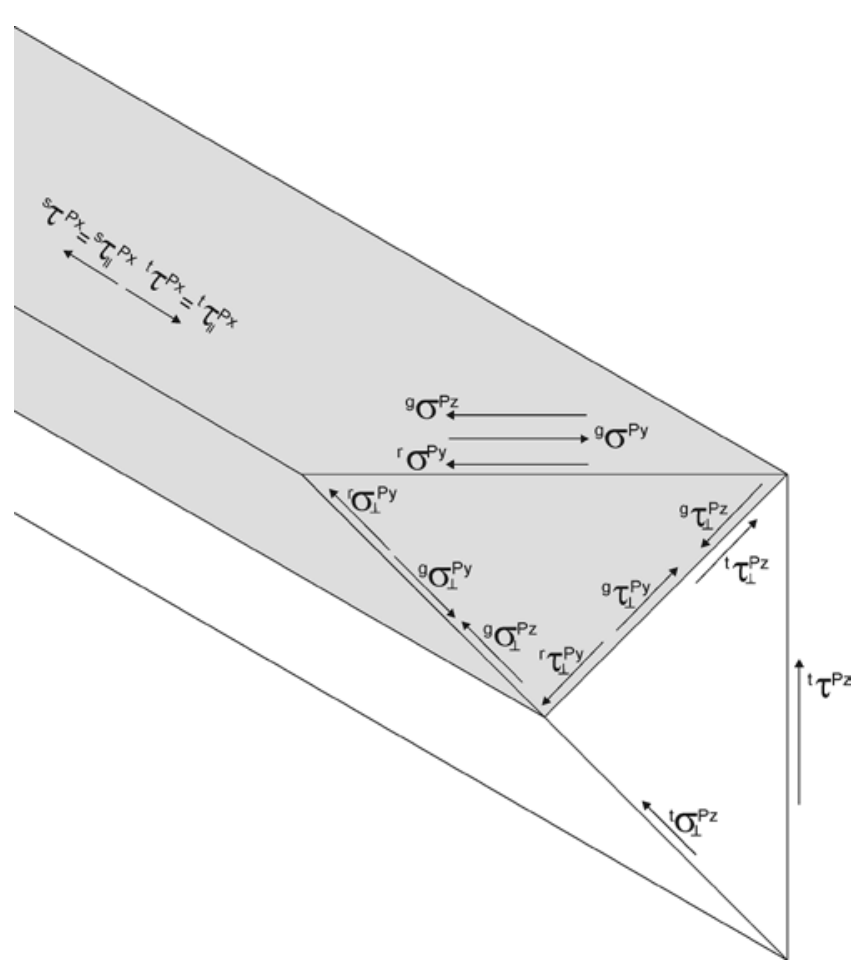

Rys. 7. Rozkład naprężeń w punkcie III spoiny pachwinowej

Fig. 7. The stress distribution at point III of the fillet joint

Zatem, analogicznie jak w punkcie l:

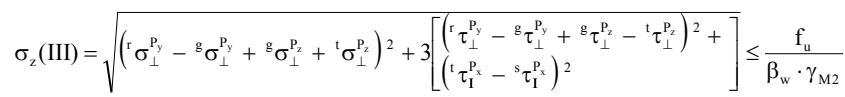

${ }^{\mathrm{r}} \sigma_{\perp}^{\mathrm{P}_{\mathrm{y}}}-{ }^{\mathrm{g}} \sigma_{\perp}^{\mathrm{P}_{\mathrm{y}}}+{ }^{\mathrm{g}} \sigma_{\perp}^{\mathrm{P}_{\mathrm{z}}}+{ }^{\mathrm{t}} \sigma_{\perp}^{\mathrm{P}_{\mathrm{z}}} \leq 0,9 \frac{\mathrm{f}_{\mathrm{u}}}{\gamma_{\mathrm{M} 2}}$
Punkt IV, rysunek 8

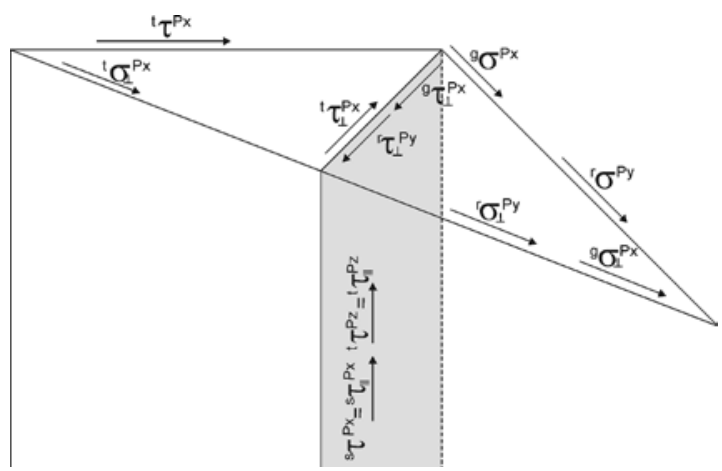

Rys. 8. Rozkład naprężeń w punkcie IV spoiny pachwinowej

Fig. 8. The stress distribution at point IV of the fillet joint

Zatem, analogicznie jak w punkcie II:

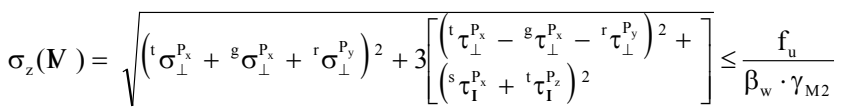

${ }^{\mathrm{t}} \sigma_{\perp}^{\mathrm{P}_{\mathrm{x}}}+{ }^{\mathrm{g}} \sigma_{\perp}^{\mathrm{P}_{\mathrm{x}}}+{ }^{\mathrm{r}} \sigma_{\perp}^{\mathrm{P}_{\mathrm{y}}} \leq 0,9 \frac{\mathrm{f}_{\mathrm{u}}}{\gamma_{\mathrm{M} 2}}$

Nawet pobieżny przegląd zależności stosowanych w metodzie kładowej i w metodzie rozkładu naprężeń wskazuje, że w metodzie kładowej dodawane są składowe naprężeń w istocie o przeciwnych zwrotach, co musi prowadzić do wspomnianego wyżej przewymiarowania spoin. Jego wielkość uzależniona jest od proporcji pomiędzy siłami $P_{x}, P_{y}$ i $P_{z}$. W przypadku konieczności obliczenia naprężeń poza wskazanymi wyżej punktami zachodzi potrzeba dokonania dalszych rozkładów naprężeń, co sprawia, że wzory są jeszcze bardziej skomplikowane.

Punkt $V$, rysunek 9

Naprężenia wynoszą:

${ }^{\mathrm{s}} \tau_{\mathrm{II}}^{\mathrm{P}_{\mathrm{x}}}={ }^{\mathrm{s}} \tau^{\mathrm{P}_{\mathrm{x}}} ;{ }^{\mathrm{t}} \tau_{\mathrm{II}}^{\mathrm{P}_{\mathrm{z}}}=\frac{\sqrt{2}}{2} \tau^{\mathrm{P}_{\mathrm{z}}} ;{ }^{\mathrm{t}} \tau^{\mathrm{P}_{\mathrm{II}}}=\frac{\sqrt{2}}{2} \tau^{\mathrm{P}_{\mathrm{x}}}$

${ }^{\mathrm{t}} \tau_{1 \perp}^{\mathrm{P}_{\mathrm{z}}}={ }^{\mathrm{t}} \sigma_{1 \perp}^{\mathrm{P}_{\mathrm{z}}}=\frac{\sqrt{2}}{2}\left(\frac{\sqrt{2}}{2}{ }^{\mathrm{t}} \tau^{\mathrm{P}_{\mathrm{z}}}\right)=\frac{1}{2}{ }^{\mathrm{t}} \tau^{\mathrm{P}_{\mathrm{z}}}$

${ }^{\mathrm{t}} \tau_{1 \perp}^{\mathrm{P}_{\mathrm{x}}}={ }^{\mathrm{t}} \sigma_{1 \perp}^{\mathrm{P}_{\mathrm{x}}}=\frac{\sqrt{2}}{2}\left(\frac{\sqrt{2}}{2}{ }^{\mathrm{t}} \tau^{\mathrm{P}_{\mathrm{x}}}\right)=\frac{1}{2}{ }^{\mathrm{t}} \tau^{\mathrm{P}_{\mathrm{x}}}$

${ }^{g} \tau_{\perp}^{\mathrm{P}_{y}}={ }^{\mathrm{g}} \sigma_{\perp}^{\mathrm{P}_{\mathrm{y}}}=\frac{\sqrt{2}}{2}\left(\frac{\sqrt{2}}{2}{ }^{\mathrm{g}} \sigma^{\mathrm{Py}_{\mathrm{y}}}\right)=\frac{1}{2}{ }^{\mathrm{g}} \sigma^{\mathrm{P}_{\mathrm{y}}}$

${ }^{\mathrm{r}} \tau_{\perp}^{\mathrm{P}_{\mathrm{y}}}={ }^{\mathrm{r}} \sigma_{\perp}^{\mathrm{P}_{\mathrm{y}}}=\frac{\sqrt{2}}{2}{ }^{\mathrm{r}} \sigma^{\mathrm{P}_{\mathrm{y}}}$

${ }^{\mathrm{g}} \tau_{\perp}^{\mathrm{P}_{\mathrm{z}}}={ }^{\mathrm{g}} \sigma_{\perp}^{\mathrm{P}_{\mathrm{z}}}=\frac{\sqrt{2}}{2}\left(\frac{\sqrt{2}}{2}{ }^{\mathrm{g}} \sigma^{\mathrm{P}_{\mathrm{z}}}\right)=\frac{1}{2}{ }^{\mathrm{g}} \sigma^{\mathrm{P}_{\mathrm{z}}}$

${ }^{g} \tau_{\perp}^{P_{x}}={ }^{g} \sigma_{\perp}^{P_{x}}=\frac{\sqrt{2}}{2}\left(\frac{\sqrt{2}}{2}{ }^{g} \sigma^{P_{x}}\right)=\frac{1}{2} \sigma^{P_{x}}$ 


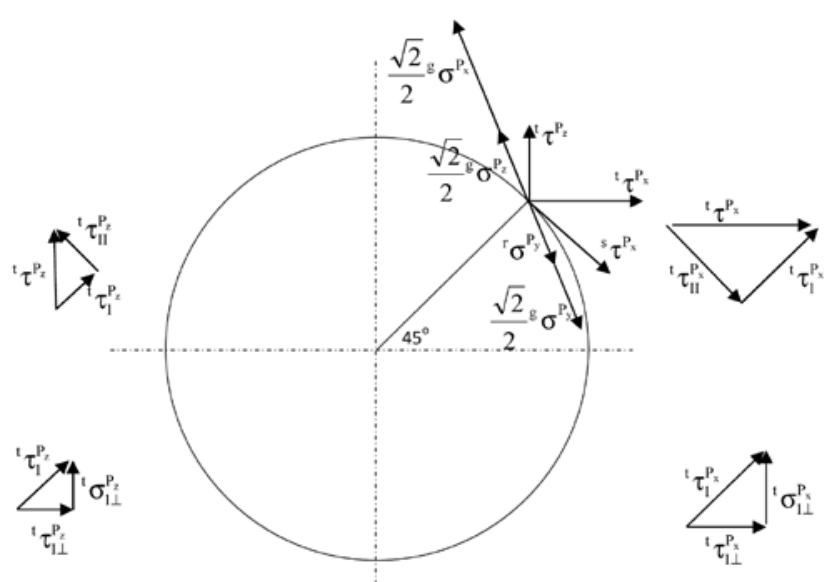

Rys. 9. Rozkład naprężeń normalnych i stycznych do płaszczyzny rysunku w punkcie $V$ obwodu spoiny pachwinowej

Fig. 9. The distribution of normal and shear stresses in the drawing plane at point $\mathrm{V}$ of the fillet joint contour

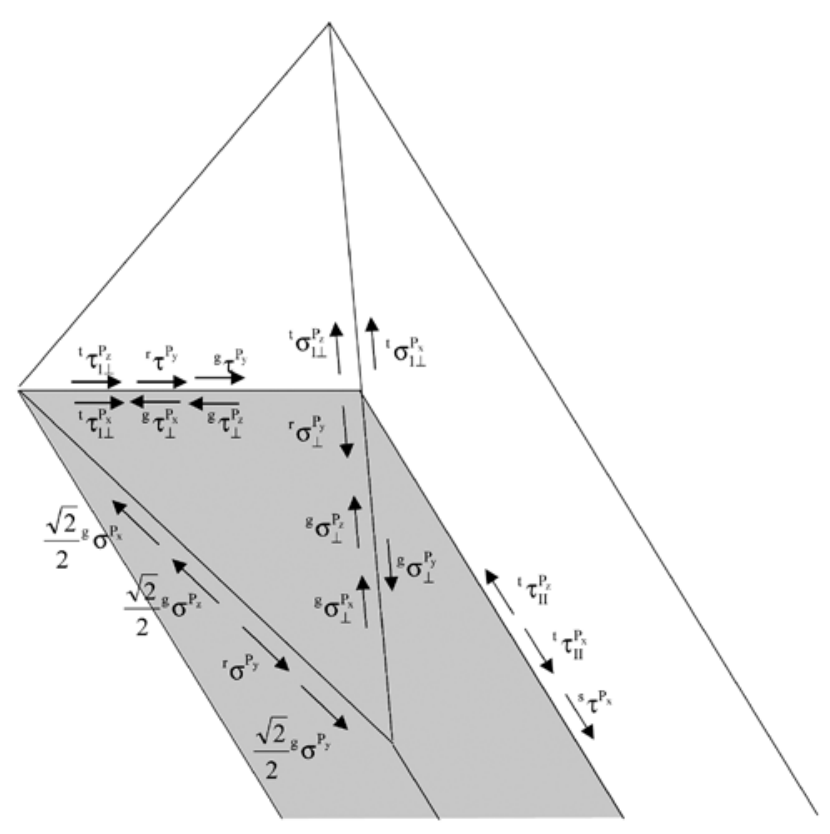

Naprężenia zastępcze w punkcie $\mathrm{V}$ wynoszą więc:

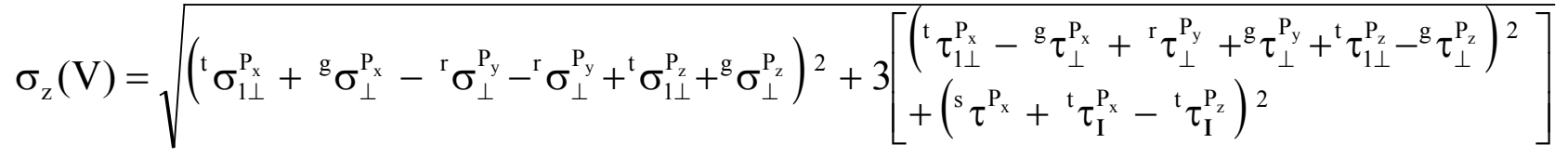

$$
\begin{aligned}
& \leq \frac{f_{u}}{\beta_{w} \cdot \gamma_{M 2}} \\
& { }^{\mathrm{t}} \sigma_{1 \perp}^{\mathrm{P}_{\mathrm{x}}}+{ }^{\mathrm{g}} \sigma_{\perp}^{\mathrm{P}_{\mathrm{x}}}-{ }^{\mathrm{r}} \sigma_{\perp}^{\mathrm{P}_{\mathrm{y}}}-{ }^{\mathrm{g}} \sigma_{\perp}^{\mathrm{P}_{\mathrm{y}}}+{ }^{\mathrm{t}} \sigma_{1 \perp}^{\mathrm{P}_{\mathrm{z}}}+{ }^{\mathrm{g}} \sigma_{\perp}^{\mathrm{P}_{\mathrm{z}}} \leq 0,9 \frac{\mathrm{f}_{\mathrm{u}}}{\gamma_{\mathrm{M} 2}}
\end{aligned}
$$

\section{Wnioski}

Należy zaznaczyć, że w przypadku kąta różnego od $45^{\circ}$, tzn. gdy jego sinus nie jest równy kosinusowi, obliczenia ulegają dalszej komplikacji, podobnie jak wtedy, gdy stosujemy pachwinowe spoiny asymetryczne. Nieefektywność wykonywania i użytkowania nierównoramiennych spoin pachwinowych została wykazana w pracy [10]. Powyższy przykład pokazuje, że metoda kierunkowa obliczania spoin pachwinowych może być żmudna, jednak należy pamiętać, że prowadzi do efektywnego i ekonomicznego projektowania i stosowania spoin pachwinowych. Ich przewymiarowywanie jest od wielu lat podstawową bolączką konstrukcji spawanych, co wobec ich ilościowej przewagi nad czołowymi (sięgającej 9:1) prowadzi do przesztywnienia, kruchości i pękania węzłów konstrukcyjnych wykonanych nawet $z$ łatwospawalnych stali.

Badania realizowane $w$ ramach Projektu „Nowoczesne technologie materiałowe stosowane w przemyśle lotniczym", Nr POIG.01.01.02-00-015/08-00 w Programie Operacyjnym Innowacyjna Gospodarka (PO IG). Projekt wspóffinansowany przez Unię Europejską ze środków Europejskiego Funduszu Rozwoju Regionalnego.

Financial support of Structural Funds in the Operational Programme - Innovative Economy (IE OP) financed from the European Regional Development Fund - Project „Modern material technologies in aerospace industry", Nr POIG.01.01.02-00-015/08-00 is gratefully acknowledged. 


\section{Literatura}

[1] Śledziewski E.: Projektowanie stalowych konstrukcji spawanych, WNT, Warszawa 1972

[2] PN-76/B-03200 Konstrukcje stalowe. Obliczenia statyczne i projektowanie.

[3] PN-80/B-03200 Konstrukcje stalowe. Obliczenia statyczne i projektowanie.

[4] PN-90/B-03200 Konstrukcje stalowe. Obliczenia statyczne i projektowanie.

[5] PN-EN 1993 1-8:2008. Eurokod 3. Projektowanie konstrukcji stalowych. Część 1-8 Projektowanie węzłów.

[6] Wojsyk K.: Analiza naprężeń obliczeniowych w spoinach pachwinowych konstrukcji spawanych. Materiały II Sympozjum Zakładów Spawalnictwa Politechnik. Poznań, maj 1980.

[7] Ferenc K., Ferenc J.: Konstrukcje spawane. Wyd. III, Warszawa, WNT 2006.

[8] Wichtowski B.: Obliczanie złączy spawanych poddawanych obciążeniom statycznym i zmęczeniowym według Eurokodu 3. Przegląd Spawalnictwa 1/2011, s. 15-22.

[9] Wojsyk K.: Przykład obliczenia naprężeń pochodzących od złożonych statycznych obciążeń zewnętrznych w spoinie pachwinowej (wg PN-90/B-03200). Spajanie materiałów konstrukcyjnych, 1(1)/2008, s. 45-48.
[10] Kudła K., Wojsyk K.: Ekonomiczne stosowanie spoin pachwinowych w konstrukcjach spawanych. Mat. Konf. „Postęp, innowacje i wymagania jakościowe procesów spajania." s. 177-186. Międzyzdroje 22-24.05.2012.

[11] Kudła K, Wojsyk K.: Metody poprawy właściwości eksploatacyjnych złączy spawanych. Przegląd Spawalnictwa 5/2012, s. $49-51$.

[12] Gawrysiuk W.: Spawanie hybrydowe (Laser-MAG) paneli ścian szczelnych kotłów energetycznych ze stali $7 \mathrm{CrMo}$ VTiB10-10. Przegląd Spawalnictwa 5/2014, s. 43-48.

[13] Wichtowski B., Wichtowski M.: Normatywne wymagania wykonawcze i spawalnicze w konstrukcjach budowlanych oraz badania jakości spoin. Przegląd Spawalnictwa 3/2012, s. 29-36.

[14] Pakos R.: Nadzór i badania stalowych konstrukcji spawanych wg PN-EN 1090-2:2009. Przegląd Spawalnictwa $3 / 2011$, s. $44-48$.

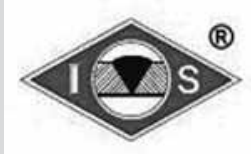

\section{W dniach od 14 do 16 października 2014 roku} Instytut Spawalnictwa w Gliwicach organizuje

56. Konferencję Naukowo-Techniczną pod hasłem: „Spawalnictwo - zawsze można więcej”. Konferencja odbędzie się równocześnie z Międzynarodowymi Targami Spawalniczymi ExpoWELDING 2014 w Centrum Targowo-Konferencyjnym Expo Silesia w Sosnowcu.

Konferencja wraz z targami spawalniczymi jest najważniejszym wydarzeniem w branży spawalniczej w tym roku w Polsce. Konferencja jest objęta patronatem Ministerstwa Gospodarki i Polskiej Akademii Nauk. W trzydniowym spotkaniu weźmie udział ok. 300 specjalistów, naukowców i praktyków w dziedzinie spawalnictwa i technologii pokrewnych. 